\title{
A study of regional cerebral blood flow and cognitive performance in Alzheimer's disease
}

\author{
John T O'Brien, Sarah Eagger, Ghulam M S Syed, Barbara J Sahakian, Raymond Levy
}

\begin{abstract}
Thirty five patients with dementia of the Alzheimer type (DAT) and 35 controls matched for age, sex and handedness were investigated using single photon emission computer tomography (SPECT) with $99 \mathrm{~m}$ technetium HMPAO. Regional cerebral blood flow (rCBF) was assessed semiquantitatively in 18 cortical and 4 subcortical areas by normalising mean information density in each region to cerebellar mean information density. Analysis revealed significantly reduced rCBF to temporal, parietal, frontal and left occipital cortex in the patients whilst blood flow to subcortical areas showed no differences between the 2 groups. In addition, significant left-sided cortical hypoperfusion was seen in the DAT group but not in controls. When patients were subdivided on the basis of disease severity, those with mild disease showed temporal, parietal and left frontal changes with more severely affected patients also showing right frontal and left occipital involvement. rCBF patterns did not distinguish between presenile and senile onset cases once duration and severity of illness were controlled. Eight cortical areas were also rated visually for perfusion deficits on a simple 4 point scale. Perfusion deficits were detected in 34 of 35 patients but in only 4 of 35 controls. In the DAT group significant correlations were found between many of the neuropsychological tests used and rCBF. Memory correlated with left temporal activity, praxis, perception, object assembly and block design with right parietal activity and language with activity throughout the left hemisphere. Significant correlations were also seen between subcortical and cortical blood flow, possibly explaining the correlations observed between many of the neuropsychological tests and thalamic blood flow.
\end{abstract}

\section{(F Neurol Neurosurg Psychiatry 1992;55:1182-1187)}

Dementia of the Alzheimer type (DAT) is associated with changes in cortical metabolism as demonstrated by the technique of positron emission tomography (PET) ${ }^{1}$ and changes in regional cerebral blood flow (rCBF) that can be detected using single photon emission computer tomography (SPECT)..$^{2-6}$ Decreased metabolism and reduced cerebral perfusion are known to occur predominantly in temporal and parietal areas - regions which at post mortem show the greatest neurochemical abnormalities. ${ }^{7}$ However, the extent to which other brain areas are involved is unclear. Marked frontal changes are seen pathologically ${ }^{8}$ and whilst some have reported reduced rCBF in frontal areas ${ }^{569}$ others have not found this. $^{3410}$ Similarly, although occipital changes have been demonstrated by PET, ${ }^{1}$ others argue the occipital lobe is spared in DAT and use it as a reference point for normalising $\mathrm{rCBF}^{5}$ Differences in $\mathrm{rCBF}$ have also been reported to distinguish between patients with presenile (age less than 65) and senile (age greater than 65) onset of the disease, ${ }^{11}$ in keeping with the concept of clinical subtyping which has been described. ${ }^{1213}$ Correlations have been noted between rCBF deficits and scores on neuropsychological tests ${ }^{35}$ although negative results have also been reported. ${ }^{14} 15$

Previous studies have generally investigated patients in the relatively late stages of the disease and have often compared rCBF in patients with only a very small control group, possibly explaining some of the discrepant results observed. The aims of this study were to investigate $\mathrm{rCBF}$ in DAT patients in the relatively early stages of the disease compared with a large group of age-matched controls and also to attempt to correlate any rCBF deficits seen with cognitive performance using more detailed neuropsychological tests than have previously been described. In clinical practice it is important to know the value of visual inspection of the scan and this study also sought to investigate the usefulness of a simple 4-point rating scale for visual assessment of regional perfusion deficits.

\section{Subjects and methods}

Patients

Thirty five right handed patients were selected from consecutive referrals to the Memory Clinic at the Maudsley Hospital. All had standardised assessment including history, physical and mental state examination, blood tests and CT. All fulfilled NINCDS/ADRDA criteria for probable Alzheimer's disease. ${ }^{16}$ Age of onset was recorded to allow separation into a senile onset (over 65 years of age) and presenile onset (less than 65 years of age) group. The presence or absence of a family history was assessed by using the appropriate questions from the Cambridge Diagnostic Examination for the Elderly (CAMDEX). ${ }^{17}$ To investigate how rCBF might change as a 


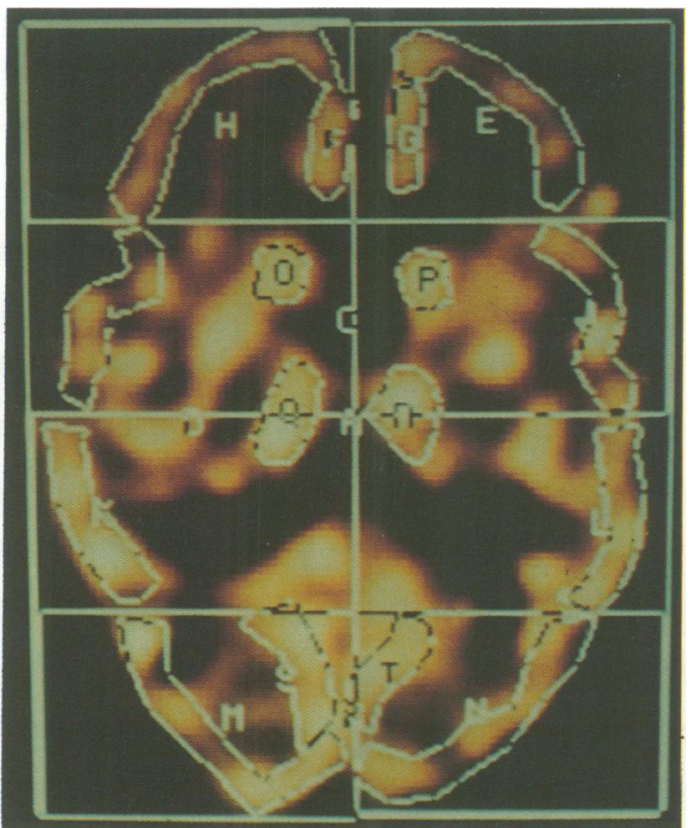

Figure 1 SPECT image of lower slice with regions of interest drawn in.

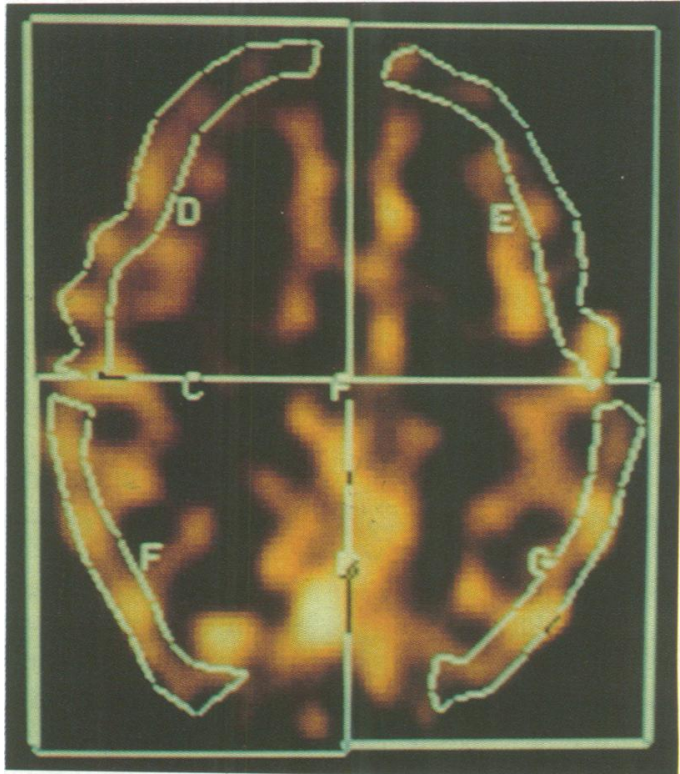

Figure 2 SPECT image of upper slice with regions of interest drawn in.

function of illness severity, patients were subdivided on the basis of their score on the Mini Mental State Examination (MMSE), ${ }^{18}$ into a mild (score greater than or equal to $20, n=14$ ) and moderate/severe (score less than $20, n=$ 21) group.

Controls

Thirty five age-matched right handed controls who had no signs or symptoms of dementia were recruited from the spouses of patients chosen for the study. Informed consent was obtained from all controls and patients and also from next of kin for the patient group. Local ethical committee and ARSAC approval was obtained. All patients and controls were drug free (for at least 3 weeks) both at the time of SPECT scanning and at the time of neuropsychological assessment.
Neuropsychological assessment

All patients and 27 controls received the Mini Mental State Examination. ${ }^{18}$ All patients were given the CAMCOG; the cognitive test component of the CAMDEX. ${ }^{17}$ The CAMCOG consists of 67 questions covering several areas of cognition. The maximum score is 107 and this can be subdivided into components covering orientation, language, attention, praxis, memory, calculation, abstract thinking and perception. For the purposes of this study, the four largest sub-components (memory, language, praxis and perception) were considered. In addition, 20 patients received a more detailed neuropsychological battery including the digit span, block design, object assembly and comprehension subtests of the WAIS, ${ }^{19}$ the Wechsler Logical Memory Scale (WMS), ${ }^{20}$ the Object Learning Test (KOLT) and the digit copying tests (KDCT) from the Kendrick Tests for the Elderly ${ }^{21}$ and the Benton Visual Retention Test. ${ }^{22}$ These tests were chosen because they have been widely used and validated in the elderly and principally examine functions subserved by temporal and parietal lobes, the areas most affected in Alzheimer's disease. For the WMS only the immediate recall score was considered because 14 out of the 20 patients tested scored 0 on delayed recall. CAMCOG assessment was performed within three months and all other neuropsychological tests within two weeks of SPECT scanning.

\section{Neuroimaging technique}

Regional cerebral blood flow was measured using technetium $99 \mathrm{~m}$ labelled hexa methyl propylene amine oxime (99m Tc HMPAO) and a dedicated brain SPECT imager (SME 810, linked to MacIntosh II computer). Each subject received an intravenous injection of $550 \mathrm{MBq}$ of $99 \mathrm{~m} \mathrm{TcHMPAO}$ while lying supine in a quiet room with eyes closed and ears unplugged. Imaging was carried out within 90 minutes of injection. Fourteen overlapping transverse slices, each $15 \mathrm{~mm}$ thick, were obtained in a plane parallel to the orbitomeatal (OM) line. Acquisition time for each slice was 3 minutes, the in-plane resolution being $7.5 \mathrm{~mm}$.

\section{Regions of interest}

The 14 slices were compared with a standard CT scan brain atlas ${ }^{23}$ to select three slices for data analysis. The first slice parallel to the OM line was selected for the cerebellum. Other slices approximately $35 \mathrm{~mm}$ above the OM line (the lower slice) and $65 \mathrm{~mm}$ above the OM line (the upper slice) were also chosen. Using the scanner's computer system, regions of interest (ROIs) were drawn by hand over the cerebellum and to delineate appropriate cortical and subcortical areas (listed in table 2). Figures 1 and 2 demonstrate how the ROIs were delineated. All ROIs were approximately 6 pixels wide $(10 \mathrm{~mm})$ in an attempt to exclude white matter and ventricular areas so that only cortical blood flow was measured and were drawn blind with regard to subject diagnosis by the same operator. Counts in each ROI were 


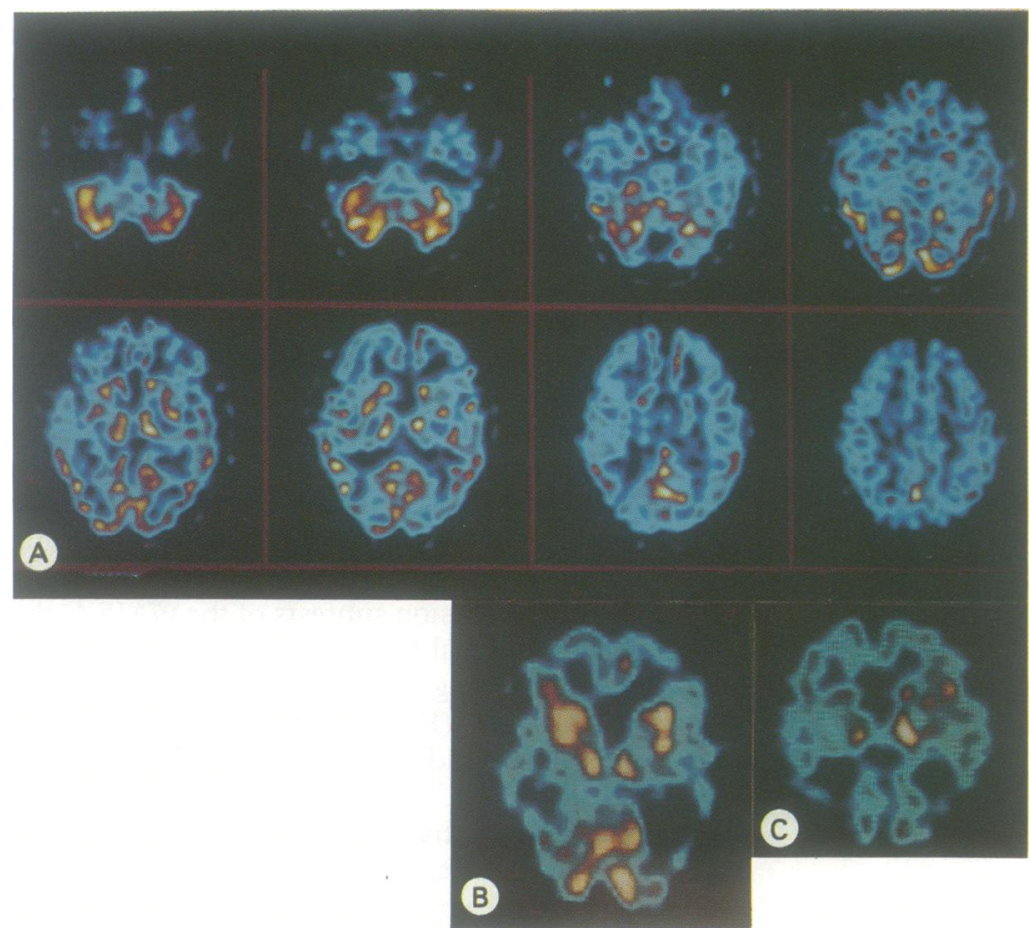

Figure 3 SPECT scans (lower slice) illustrating, a) normal control, b) characteristic temporo-parietal perfusion deficit in DAT (note that this patient also demonstrates left sided hypoperfusion), c) marked occipital perfusion deficit in DAT patient.

divided by the area in pixels to derive mean information density (MID) which represented mean uptake of $99 \mathrm{~m}$ Tc HMPAO in that region. A relative measure of blood flow was obtained by dividing MID in each region to cerebellar MID. Scans were also rated visually (with images normalised to peak activity in the slice) on a 4-point rating scale for perfusion deficits, 0 - representing normal perfusion, 1 mild perfusion deficit (approximately 10\%), 2 - moderate perfusion deficit (approximately $20 \%$ ) and 3 - severe perfusion deficit (30\% or more). Eight cortical regions were chosen for this purpose: right and left frontal, right and left temporal, right and left parietal and right and left occipital. For perfusion deficits all scans were also rated blind with regard to clinical grouping of subjects by the same operator.

\section{Statistical analysis}

Regional cerebral blood flow was compared between patients and controls using independent $t$ tests. One way analysis of variance was used for comparisons within the patient group (presenile against senile, family history against no family history, mild against moderate). Analysis of variance with repeated measures (using diagnosis as a "between subjects" factor and region and side as "within subject" factors) was used to compare blood flow asymmetries between left and right hemispheres in the 2 groups. Visual perfusion scores represented ranked data and these were analysed nonparametrically using the Mann Whitney $U$ test. A significance level of $p<0.05$ was accepted. Correlations were considered between regional cerebral blood flow and cognitive test scores using Pearson's correlation. If the very conservative Bonferroni correction were applied to the correlations, $\mathrm{p} \leq 0.01$ would be equivalent to overall $a=0.6$ and $\mathrm{p} \leq 0.001$ to overall $a=$ 0.06 .

\section{Results}

All subjects and controls successfully completed the procedure and no adverse events were reported. Table 1 gives subject characteristics. There was no significant difference in age or sex ratio between the two groups. Regional cerebral blood flow for all areas is shown in table 2. There were no differences between groups in the four subcortical areas examined but reduced flow was seen in the patient group in all cortical regions except right and left visual cortex, right high frontal and right occipital areas. When patients with mild DAT (MMSE $\geq 20$ ) were compared with more severely affected patients (MMSE < 20), differing patterns of rCBF deficits were seen as shown in table 3 . When compared with controls mild DAT patients showed predominantly temporal and parietal deficits, although left frontal changes were also seen. The more severely affected patients showed more pronounced temporal, parietal and frontal changes but also had significantly reduced flow to left occipital cortex (see fig 3). There was a trend toward reduced blood flow to the right occipital cortex which just failed to reach significance $(p=0.059)$. With regard to asymmetry of blood flow, analysis of variance revealed a significant diagnosis by side interaction $(\mathrm{F}=4.85, \mathrm{df}=1,66 \mathrm{p}=0.031)$ which indicated relative left sided hypoperfusion in the DAT patients but not the controls. The asymmetry in blood flow did not appear to vary as a function of severity because analysis of variance comparing asymmetry difference between the mild and moderate/severe group revealed no significant differences.

No differences in $\mathrm{rCBF}$ were seen that separated groups with or without a family history of dementia. When comparisons were made between senile and presenile onset groups, initially right occipital hypoperfusion was seen in the presenile group $(F=5 \cdot 26$, df1, $33, p=0.028)$. However, when the analysis was repeated using severity and duration of illness as covariates this difference was no longer found to be significant.

A summary of perfusion scores is shown in table 4. All the DAT patients except one showed some perfusion deficits compared with only 4 controls $\left(\chi^{2}=48.4, \mathrm{df}=1, \mathrm{p}<0.0001\right)$. The DAT patient who showed no perfusion deficits was a mildly affected case (MMSE =

Table 1 Subject characteristics

\begin{tabular}{llll}
\hline & & $\begin{array}{l}\text { Controls } \\
(n=35)\end{array}$ & $\begin{array}{l}\text { DAT } \\
\text { patients } \\
(n=35)\end{array}$ \\
\hline Age & mean (SD) & $\begin{array}{l}63 \cdot 9(6 \cdot 8) \\
\text { range }\end{array}$ & $\begin{array}{l}49-77 \\
56 \cdot 6(5 \cdot 9)\end{array}$ \\
Sex & male:female & $14: 21$ & $20: 15$ \\
MMSE score & mean (SD) & $29 \cdot 1(0 \cdot 9)$ & $17 \cdot 1(5 \cdot 6)$ \\
CAMCOG & range (SD) & $27-30$ & $7-27$ \\
score & mean (SD) & - & $62 \cdot 5(17 \cdot 6)$ \\
& range & - & $19-88$ \\
\hline
\end{tabular}


Table 2 Mean (SD) of regional blood flow for patients and controls

\begin{tabular}{llll}
\hline Region & $\begin{array}{l}\text { Controls } \\
n=35\end{array}$ & $\begin{array}{l}D A T \\
n=35\end{array}$ & $p$ value \\
\hline Whole slice (lower) & $0.77(0.04)$ & $0.71(0.06)$ & 0.0001 \\
Whole slice (upper) & $0.73(0.03)$ & $0.67(0.06)$ & 0.0001 \\
Right frontal (lower) & $0.82(0.05)$ & $0.78(0.06)$ & 0.003 \\
Left frontal (lower) & $0.82(0.05)$ & $0.75(0.07)$ & 0.0001 \\
Right frontal (upper) & $0.80(0.06)$ & $0.78(0.07)$ & $0.189 \mathrm{NS}$ \\
Left frontal (upper) & $0.80(0.05)$ & $0.75(0.07)$ & 0.0001 \\
Right anterior temporal & $0.87(0.06)$ & $0.79(0.08)$ & 0.0001 \\
Left anterior temporal & $0.86(0.04)$ & $0.77(0.08)$ & 0.0001 \\
Right posterior temporal & $0.87(0.05)$ & $0.77(0.07)$ & 0.0001 \\
Left posterior temporal & $0.86(0.05)$ & $0.75(0.10)$ & 0.0001 \\
Rigth parietal & $0.81(0.06)$ & $0.73(0.09)$ & 0.0001 \\
Left parietal & $0.81(0.05)$ & $0.72(0.07)$ & 0.0001 \\
Right occipital & $0.80(0.05)$ & $0.77(0.09)$ & $0.059 \mathrm{Ns}$ \\
Left occipital & $0.79(0.06)$ & $0.74(0.1)$ & 0.007 \\
Right medial frontal & $0.86(0.07)$ & $0.82(0.08)$ & 0.029 \\
Left medial frontal & $0.85(0.08)$ & $0.81(0.09)$ & 0.038 \\
Right visual cortex & $0.96(0.06)$ & $0.95(0.1)$ & $0.594 \mathrm{NS}$ \\
Left visual cortex & $0.97(0.05)$ & $0.94(0.1)$ & $0.159 \mathrm{NS}$ \\
Right caudate & $0.94(0.07)$ & $0.95(0.09)$ & $0.637 \mathrm{NS}$ \\
Left caudate & $0.92(0.07)$ & $0.94(0.09)$ & $0.292 \mathrm{NS}$ \\
Right thalamus & $0.95(0.07)$ & $0.94(0.09)$ & $0.938 \mathrm{NS}$ \\
Left thalamus & $0.94(0.07)$ & $0.91(0.09)$ & $0.261 \mathrm{NS}$ \\
\hline
\end{tabular}

Table 3 Mean (SD) of regional blood flow for mild and moderate cases

\begin{tabular}{|c|c|c|c|}
\hline & \multicolumn{3}{|c|}{ Alzheimer's disease } \\
\hline & $\begin{array}{l}\text { Mild } \\
D A T \\
n=14\end{array}$ & $\begin{array}{l}\text { Mod/severe } \\
D A T \\
n=21\end{array}$ & $\begin{array}{l}p \text { value } \\
\text { Mild v } \\
\mathrm{mod} / \mathrm{severe}\end{array}$ \\
\hline $\begin{array}{l}\text { Whole slice (lower) } \\
\text { Whole slice (upper) } \\
\text { Right frontal (lower) } \\
\text { Left frontal (lower) } \\
\text { Right frontal (upper) } \\
\text { Left frontal (upper) } \\
\text { Right anterior temporal } \\
\text { Left anterior temporal } \\
\text { Right posterior temporal } \\
\text { Left posterior temporal } \\
\text { Rigth parietal } \\
\text { Left parietal } \\
\text { Right occipital } \\
\text { Left occipital } \\
\text { Right medial frontal } \\
\text { Left medial frontal } \\
\text { Right visual cortex } \\
\text { Left visual cortex } \\
\text { Right caudate } \\
\text { Left caudate } \\
\text { Right thalamus } \\
\text { Left thalamus }\end{array}$ & $\begin{array}{l}0.72(0.04) \ddagger \\
0.69(0.05) \dagger \\
0.78(0.06) \\
0.78(0.06) \dagger \\
0.80(0.07) \\
0.76(0.06) \\
0.79(0.07) \ddagger \\
0.80(0.07) \ddagger \\
0.81(0.06) \ddagger \\
0.80(0.08) \dagger \\
0.78(0.08) \\
0.75(0.07) \dagger \\
0.79(0.08) \\
0.77(0.08) \\
0.82(0.05) \dagger \\
0.81(0.07) \\
0.98(0.1) \\
0.97(0.08) \\
0.97(0.1) \\
0.95(0.09) \\
0.98(0.09) \\
0.95(0.09)\end{array}$ & $\begin{array}{l}0.70(0.07) \ddagger \\
0.66(0.06) \ddagger \\
0.77(0.06) \ddagger \\
0.72(0.06) \ddagger \\
0.77(0.07) \\
0.74(0.07) \ddagger \\
0.79(0.08) \ddagger \\
0.76(0.08) \ddagger \\
0.75(0.08) \ddagger \\
0.71(0.01) \ddagger \\
0.70(0.09) \ddagger \\
0.69(0.06) \ddagger \\
0.75(0.09) \ddagger \\
0.71(0.11) \ddagger \\
0.83(0.09) \\
0.81(0.10) \\
0.93(0.09) \\
0.92(0.11) \\
0.93(0.08) \\
0.94(0.09) \\
0.92(0.08) \\
0.89(0.08) \dagger\end{array}$ & $\begin{array}{l}\text { NS } \\
\text { NS } \\
\text { NS } \\
0 \cdot 021 \\
\text { NS } \\
\text { NS } \\
\text { NS } \\
\text { NS } \\
0 \cdot 026 \\
0 \cdot 005 \\
0 \cdot 007 \\
0 \cdot 024 \\
\text { NS } \\
\text { NS } \\
\text { NS } \\
\text { NS } \\
\text { NS } \\
\text { NS } \\
\text { NS } \\
\text { NS } \\
\text { NS } \\
\text { NS }\end{array}$ \\
\hline
\end{tabular}

tp $<0.05$ compared with controls.

$\neq \mathrm{p}<0.01$ compared with controls.

Table 4 Perfusion scores for each region (summed over all cases)

\begin{tabular}{|c|c|c|c|c|}
\hline & $\begin{array}{l}\text { Controls } \\
n=35\end{array}$ & $\begin{array}{l}D A T \\
\mathrm{n}=35\end{array}$ & $\begin{array}{l}\text { Mild DAT } \\
\mathrm{n}=14\end{array}$ & $\begin{array}{l}\text { Mod/Severe DAT } \\
\mathrm{n}=21\end{array}$ \\
\hline $\begin{array}{l}\text { Right frontal } \\
\text { Left frontal } \\
\text { Right temporal } \\
\text { Left temporal } \\
\text { Right parietal } \\
\text { Left parietal } \\
\text { Right occipital } \\
\text { Left occipital }\end{array}$ & $\begin{array}{l}1 \\
0 \\
0 \\
2 \\
0 \\
3 \\
0 \\
0\end{array}$ & $\begin{array}{l}13 \\
16 \\
27 \\
37 \\
27 \\
35 \\
18 \\
25\end{array}$ & $\begin{array}{r}4 \\
1 \\
8 \\
10 \\
8 \\
6 \\
6 \\
3\end{array}$ & $\begin{array}{r}9 \\
15 \\
19 \\
27 \\
19 \\
12 \\
12 \\
22\end{array}$ \\
\hline Total score & $\overline{6}$ & $\overline{211}$ & 52 & 159 \\
\hline
\end{tabular}

Table 5 Correlations between cognitive performance and regional cerebral blood flow in $D A T$ patients, $n=34$

\begin{tabular}{|c|c|c|c|c|c|c|}
\hline & $M M S E$ & $C A M C O G$ & $M E M$ & $L A N G$ & PRAXIS & PERCEPT \\
\hline $\begin{array}{l}\text { Right frontal (lower) } \\
\text { Left frontal (lower) } \\
\text { Right posterior temporal } \\
\text { Left Posterior temporal } \\
\text { Right parietal } \\
\text { Left parietal } \\
\text { Right occipital } \\
\text { LEft occipital } \\
\text { Right thalamus } \\
\text { Left thalamus }\end{array}$ & $\begin{array}{l}\text { NS } \\
0 \cdot 48^{\star} \\
0 \cdot 50^{\star} \\
0 \cdot 60^{\star \star} \\
0 \cdot 54^{\star \star} \\
0 \cdot 55^{\star \star} \\
N S \\
0 \cdot 41^{\star} \\
0.44^{\star} \\
0.45^{\star}\end{array}$ & $\begin{array}{l}\text { NS } \\
0.47^{\star} \\
\text { NS } \\
0.52^{\star \star} \\
0.52^{\star \star} \\
0.48^{\star} \\
\text { NS } \\
0.41^{\star} \\
0.41^{\star} \\
0.53^{\star \star}\end{array}$ & $\begin{array}{l}\text { NS } \\
\text { NS } \\
\text { NS } \\
0 \cdot 45^{\star} \\
\text { NS } \\
\text { NS } \\
\text { NS } \\
\text { NS } \\
\text { NS } \\
\text { NS }\end{array}$ & $\begin{array}{l}\text { NS } \\
0 \cdot 56^{\star \star} \\
\text { NS } \\
0 \cdot 51^{\star} \\
\text { NS } \\
0 \cdot 41^{\star} \\
\text { NS } \\
\text { NS } \\
\text { NS } \\
0 \cdot 47^{\star}\end{array}$ & $\begin{array}{l}\text { NS } \\
\text { NS } \\
\text { NS } \\
\text { NS } \\
0.56^{\star \star} \\
\text { NS } \\
\text { NS } \\
\text { NS } \\
\text { NS } \\
0.53^{\star \star}\end{array}$ & $\begin{array}{l}\text { NS } \\
\text { NS } \\
\text { NS } \\
\text { NS } \\
0 \cdot 42^{\star} \\
\text { NS } \\
\text { NS } \\
\text { NS } \\
\text { NS } \\
0.43^{\star}\end{array}$ \\
\hline
\end{tabular}

${ }^{\star} \mathrm{p}<0.01$

${ }_{\star \star} p<0.01$
${ }^{\star} p<0.001$
22, CAMCOG $=81$ ). Thirty three out of 35 patients had total perfusion scores of 2 or more (total perfusion score is the summed score for all eight cortical areas). Of the four control subjects showing any perfusion deficits, two subjects had a perfusion score of 1 and two of 2. Consistent with the semi-quantitative analysis, greatest perfusion deficits were seen in temporo-parietal areas although frontal and occipital deficits were also apparent. Nonparametric analysis revealed significant differences between DAT patients and controls for all the cortical areas examined ( $p<0.005$ for all regions).

Significant correlations were seen between regional cerebral blood flow and cognitive tests (tables 5 and 6). Among the subcomponents of the CAMCOG, memory correlated with blood flow to the left temporal lobe, praxis and perception with blood flow to the right parietal area and language to blood flow to left temporal, parietal and frontal areas. Significant correlations were also seen between cognitive scores and both thalamic areas, but particularly with the left thalamus. Thalamic blood flow was also found to correlate significantly with cortical blood flow $[\mathrm{r}=0.68, \mathrm{p}<0.001$ for both right and left thalami when compared to whole slice (upper) blood flow]. Among the more traditional neuropsychological tests (table 6), significant correlations were also seen. Block design and object assembly correlated with blood flow to the right parietal area, the Benton Visual Retention Test and the digit copying test correlated with parietal flow bilaterally. Digit span correlated with many cortical areas but perhaps surprisingly the Wechsler Memory Scale did not correlate with any cortical area.

\section{Discussion}

This study has helped to further define the pattern of rCBF deficits seen in patients with DAT and has helped clarify some of the controversies apparent in the literature. Reduced blood flow was seen in most of the cortical but none of the subcortical areas examined, consistent with pathological findings of predominantly cortical involvement in Alzheimer's disease. ${ }^{24}$ Decreased cortical blood flow was predominantly seen in temporal and parietal regions, in keeping with previous SPECT work. However, this study also demonstrated significant frontal and occipital hypoperfusion in the patient group, both on quantification analysis and on visual inspection of scans. When the patient group was subdivided according to severity, mildly affected patients showed temporal, parietal and some frontal changes with more severely affected cases also showing decreased blood flow to the occipital areas. The finding of frontal changes, even in those in the relatively early stages of the disease, argues against the notion that frontal changes are only seen in severe cases. ${ }^{25}$ The recognition that frontal changes can occur early in the course of Alzheimer's disease is an important cautionary feature with regard to differential diagnosis of Alzheimer's against 
Table 6 Correlations between cognitive subtests and regional cerebral blood flow in DAT patients, $n=20$

\begin{tabular}{|c|c|c|c|c|c|c|c|}
\hline & $K O L T$ & $K D C T$ & $W M S$ & $\begin{array}{l}\text { Digit } \\
\text { span }\end{array}$ & $\begin{array}{l}\text { Block } \\
\text { design }\end{array}$ & $\begin{array}{l}\text { Object } \\
\text { assembly }\end{array}$ & Benton \\
\hline $\begin{array}{l}\text { Right frontal (lower) } \\
\text { Left frontal (lower) } \\
\text { Right posterior temporal } \\
\text { Left posterior temporal } \\
\text { Right parietal } \\
\text { Left parietal } \\
\text { Right occipital } \\
\text { Left occipital } \\
\text { Right thalamus } \\
\text { Left thalamus }\end{array}$ & $\begin{array}{l}\text { NS } \\
0 \cdot 54^{\star} \\
\text { NS } \\
0 \cdot 63^{\star} \\
\text { NS } \\
\text { NS } \\
0 \cdot 52^{\star} \\
\text { NS } \\
\text { NS } \\
\text { NS }\end{array}$ & $\begin{array}{l}\text { NS } \\
\text { NS } \\
\text { NS } \\
\text { NS } \\
0 \cdot 60^{\star} \\
0 \cdot 68^{\star} \\
\text { NS } \\
\text { NS } \\
\text { NS } \\
\text { NS }\end{array}$ & $\begin{array}{l}\text { NS } \\
\text { NS } \\
\text { NS } \\
\text { NS } \\
\text { NS } \\
\text { NS } \\
\text { NS } \\
\text { NS } \\
\text { NS } \\
\text { NS }\end{array}$ & $\begin{array}{l}\text { NS } \\
0 \cdot 57^{\star} \\
0 \cdot 76^{\star \star} \\
0 \cdot 70^{\star \star} \\
0 \cdot 55^{\star} \\
0 \cdot 71^{\star \star} \\
\text { NS } \\
\text { NS } \\
\text { NS } \\
0 \cdot 65^{\star}\end{array}$ & $\begin{array}{l}\text { NS } \\
\text { NS } \\
\text { NS } \\
\text { NS } \\
0 \cdot 78^{\star \star} \\
\text { NS } \\
\text { NS } \\
\text { NS } \\
\text { NS } \\
\text { NS }\end{array}$ & $\begin{array}{l}\text { NS } \\
\text { NS } \\
\text { NS } \\
\text { NS } \\
0 \cdot 59^{\star} \\
\text { NS } \\
\text { NS } \\
\text { NS } \\
\text { NS } \\
\text { NS }\end{array}$ & $\begin{array}{l}\text { NS } \\
\text { NS } \\
\text { NS } \\
\text { NS } \\
0.59^{\star} \\
0.63^{\star} \\
\text { NS } \\
\text { NS } \\
\text { NS } \\
0.58^{\star}\end{array}$ \\
\hline
\end{tabular}

frontal and other types of dementias. However, in our patient group there were no cases of isolated frontal perfusion deficits as all those with frontal changes detected on visual inspection also had temporo-parietal deficits. SPECT scans were therefore consistent with the clinical picture as no patient had a history suggestive of a frontal dementia. The finding of decreased occipital perfusion supports previous work $^{6}$ and strongly suggests that the occipital lobe is not a suitable place to choose as a reference area with which to normalise regional cerebral blood flow, particularly in patients with more severely advanced disease.

As well as decreased cortical blood flow in DAT patients, a difference in perfusion asymmetry was observed with relative left-sided hypoperfusion in the DAT group but not the controls. Pathological studies have demonstrated that whilst cholinergic function, plaques and tangles are generally symmetric, some patients do show asymmetry. ${ }^{26}$ However, pathologically asymmetries do not generally favour either hemisphere. ${ }^{27}$ Left-sided hypoperfusion has been reported in presenile onset patients, ${ }^{6}$ though opposite results have also been found. ${ }^{28}$ Separate analysis of presenile and senile groups demonstrated that the leftsided hypoperfusion found in this study was not simply due to the group of presenile onset cases included. It is also interesting that in SPECT studies involving pharmacological activation by physostigmine in patients with DAT, all have reported a greater effect on the left hemisphere than the right. ${ }^{42930}$ The cause of the asymmetry noted in this and other studies is not known, though before drawing firm conclusions it must always be remembered that patient selection is not a random process and might affect results. For instance, in this study it is possible that patients with predominantly left hemisphere involvement might be more likely to be referred to a national centre for further evaluation, perhaps because the clinical feature of dysphasia is so striking. Further SPECT and pathological studies on community samples of patients with DAT are needed to address the issue of disease asymmetry.

This study demonstrated no difference in rCBF patterns that differentiated between presenile or senile onset disease. Burns et $a l^{3}$ found that early age of onset correlated with lower activity in left posterior parietal lobe. Jagust et $a l^{11}$ found left frontal hypoperfusion in early onset cases and Habert ${ }^{6}$ found that presenile cases had significantly lower biparietal and left temporo-occipital perfusion ratios. However, all three studies are confounded by the fact that the presenile group also had more severe illness than the senile group. In this study, an initial difference between presenile and senile onset cases disappeared when data was reanalysed covarying for severity and duration of illness. It is most important in future studies investigating possible differences between putative subtypes of Alzheimer's disease that these factors are taken into account. However, given the large number of SPECT studies that now exist investigating patients with Alzheimer's disease and the lack of agreement on specific rCBF deficits to support subtyping, it seems reasonable to conclude, in accordance with our findings, that SPECT will not prove to be a useful way of distinguishing between presenile and senile onset disease processes.

Clinically, visual inspection of scans is likely to be of greater practical importance for individual patient management than quantification analysis. The four point visual rating system we have described is a simple and quick way of assessing scans. Thirty four out of 35 DAT patients showed some perfusion deficits compared with only 4 out of 35 controls. All patients did, of course, already have clear clinical diagnoses of Alzheimer's disease so it remains to be seen how useful SPECT scans would be in helping to diagnose cases where the clinical diagnosis is in doubt. However, these patients were in the relatively early stages of the disease and the proportion of abnormal scans $(97 \%)$ is considerably higher than the $75-80 \%$ of CT scans that are reported to be abnormal in cases of similarly diagnosed Alzheimer's disease, ${ }^{31}$ suggesting that SPECT may be a more useful investigation than CT for differentiating between normality and dementia.

Good correlations were found between rCBF deficits and the neuropsychological tests used in agreement with previous reports. ${ }^{3}$ The failure of some other groups to find similar correlations $^{1415}$ might be explicable in terms of inadequate numbers of subjects studied, the use of a group with too great a severity of illness or the choice of the occipital lobe as a point of reference for normalising rCBF. For example, Montaldi et $a l^{5}$ found no correlation between the memory subcomponent of the CAMCOG and perfusion to the temporal lobes and argued that either their patient group 
was too severely impaired or that the CAMCOG is too non-specific a neuropsychological tool to find such correlations. In our study a significant correlation was seen between CAMCOG memory score and blood flow to the left temporal lobe. Correlations were also seen between praxis and perception subscores and right parietal lobe flow and language and blood flow to all parts of the left hemisphere. More traditional and detailed neuropsychological tests did not appear to give higher correlations. In fact, no correlation was seen between the Wechsler Memory Scale immediate recall score and blood flow to the temporal lobe, in spite of the fact that no floor or ceiling effects appeared to operate. Our results would suggest that the CAMCOG can be an appropriate tool for neuropsychological investigation of patients with Alzheimer's disease, at least for those in the early to moderate stages of the illness. As well as correlations with cortical areas, several cognitive tests correlated with thalamic blood flow. The subcortex is generally spared in Alzheimer's disease, though thalamic involvement has been reported. ${ }^{24}$ However, in our study rCBF was not significantly reduced to the thalamus, arguing against a thalamic involvement in our patients. The thalamus projects widely to most cortical areas and the finding that thalamic blood flow correlated highly with cortical blood flow, both in patients and controls, might account for the correlations observed.

We have illustrated rCBF deficits in a group of patients with relatively early DAT. We have also demonstrated that these changes can be detected by simple visual inspection in almost all cases. As SPECT is likely to be of use and importance in the diagnosis and classification of early cases of dementia, it is recommended that future studies should concentrate on the investigation of such cases, rather than also including those late in the course of the disease, when factors such as cerebral atrophy and other changes might complicate interpretations of rCBF deficits.

We thank John Barratt for help with this study. We are grateful to Lissa Crayton, Stephen Boddington, Helena Crockford and Maureen Crooks for help with patient testing, Nicola Morant for computer help, Margaret Derrick and Marian Ryde for secretarial assistance and Alistair Burns for comments.

1 Frackowiak R, Pozzilli C, Legg N, Boulay G, Marshall J, Jones $T$. Regional cerebral oxygen supply and utilisation in dementia. Brain 1981;104:753-78.

2 Gemmell H, Sharp O, Besson J. Differential diagnosis in dementia using the cerebral blood flow agent $99 \mathrm{~m}$ TC HMPAO: a Spect study. $f$ Comp Assis Tomog, 1987;11:398-402.

3 Burns A, Philpot M, Costa D, Ell P, Levy R. The investigation of Alzheimer's disease with single photon emission tomography. $f$ Neurol Neurosurg Psychiatry 1989;52:248-53.

4 Geaney D, Soper N, Shepstone B, Cowen P. The effect of central cholinergic stimulation on regional cerebral blood flow in Alzheimer's disease studied by single photon emission tomography. Lancet 1990;335:1484-7.

5 Montaldi D, Brooks D, McColl J, Wyper D, Patterson J Barron E, McCulloch J. Measurements of regional cerebral blood flow and cognitive performance in Alzheimer's disease. I Neurol Neurosurg Psychiatry 1990; 53:33-8.

6 Habert M, Spampinato U, Mas J, et al. A comparative technetium $99 \mathrm{~m}$ hexamethylpropylene amine oxime SPET study in different types of dementia. Europ $f$ Nuclear Med 1991;18:3-11.

7 Najlerahim A, Bowen D. Biochemical measurements in Alzheimer's Disease reveal a necessity for improved neuroimaging techniques to study metabolism. Biochemi $\mathcal{f}$ 1988;251:305-8.

8 Van Hoesen G, Damasio A. Neural correlates of cognitive impairment in Alzheimer's Disease. In: Mountcastle V, Plum F, Greiger S, eds. Handbook of Physiology Sect 1, Vol 5. 1987;871-98.

9 Johnson K, Mueller S, Walshe T, English R, Holman B. Cerebral perfusion imaging in Alzheimer's disease. Arch Neurol 1987;44:165-8.

10 Hunter R, McLuskie $R$, Wyper $D$, et al. The pattern of function-related regional cerebral blood flow investigated by single photon emission tomography with $99 \mathrm{~m} \mathrm{Tc}$ HMPAO in patients with presenile Alzheimer's disease and Korsakoff's psychosis. Psycholog Med 1989; and Korsat

11 Jagust W, Reed B, Seab J, Budinger T. Alzheimer's Disease. Age at Onset and Single Photom Emission Computed Tomographic Patterns of Regional Cerebral Blood Flow. Arch Neurol 1990;47:628-33.

12 Seltzer B and Sherwin I. A comparison of clinical features in early and late onset primary degenerative dementia. Arch Neurol 1983;40:143-6.

13 Mayeux R, Stern Y, Spanton S. Heterogeneity in dementia of the Alzheimer type: evidence of subgroups. Neurology 1985;35:453-61.

14 Perani D, Di Piero V, Vallar G, et al Technetium - 99m HMPAO-SPECT study of regional cerebral perfusion in early Alzheimer's disease. fournal Nuclear Med 1988; 29:1507-14.

15 Deutsch G, Tweedy J. Cerebral blood flow in severitymatched Alzheimer and multi-infarct patients. Neurology 1987;37:431-8.

16 McKhann G, Drachman D, Folstein M, Katzman R, Price D, Stadlan E. Clinical diagnosis of Alzheimer's Disease: report of the NINCDS-ADRDA work group under the auspices of the Dept. of Health and Human Task Force in Alzheimer's Disease. Neurology 1984;34:939-44.

17 Roth M, Tym E, Mountjoy C, Huppert F, Hendrie H, Verma $S$ and Goddard R. CAMDEX: a standardised instrument for the diagnosis of mental disorder in the elderly with special reference to the early detection of elderly with special reference to the early

18 Folstein M, Folstein S, McHugh P. "Mini-mental state" a practical method for grading the cognitive state of patients for the clinician. $f$ Psychiatric Res 1975;12:189-98.

19 Wechsler D, Stone C. The Manual Wechsler Memory Scale New York: Psychological Corporation, 1973.

20 Wechsler D, Stone C. The Wechsler Memory Scale (WMS) Manual. New York: Psychological Corporation, 1973.

21 Kendrick D. Kendrick Cognitive Tests for the elderly. NFER-Nelson: Windsor, 1985

22 Benton A. RevisedVisual Retention Test 4th ed. The New York: Psychological Corporation, 1974.

23 Hanaway J, Scott W, Strother C. Atlas of the Human Brain and the Orbit for Computed Tomography. 2nd edition, 1980. St Louis, Missouri: Warren H Green.

24 Lantos P. Ageing and Dementias. Chapter in systematic pathology (3rd ed) Vol 4: In Weller R, ed. Nervous system, muscle and eyes. Edinburgh, Churchill Livingstone: 1990

25 Frlich L, Eilles C, Ihl R, Maurer K, Lancjik M. Stagedependent reductions of regional cerebral blood flow measured by HMPAO-SPECT in Dementia of Alzheimer Type. Psychiatry Res 1989;29:347-50.

26 Moossy J, Zubenko G, Martinez J, Rao G, Kopp U, Hanin I. Lateralisation of brain morphologic and cholinergic abnormalities in Alzheimer's disease. Arch Neurol 1989;46:639-42.

27 Rossor M, Iversen L, Reynolds G. Neurochemical characteristics of early and late onset types of Alzheimer's disease. BMJ 1984;288:961-4.

28 Koss E, Friedland R, Ober B, Jagust W. Differences in lateral hemispheric asymmetries of glucose utilisation between early and late-onset Alzheimer-type dementia. Ame Fl Psychiatry 1985;142:638-40.

29 Gustafson L, Edvinsson L, Dahlgren N, et al. Intravenous physostigmine treatment of Alzheimer's disease evaluated by psychometric testing, regional cerebral blood flow rCBF) measurement, and EEG. Psychopharmacol 1987;93:31-35.

30 Hunter R, Wyper D, Patterson J, Hansen M, Goodwin G. Cerebral pharmacodynamics of physostigmine in Alzheimer's disease investigated using Single Photon Computerised Tomography. Bri $\mathcal{F}$ Psychiatry 1991;158:351-7.

31 Damasio H, Eslinger P, Damasio A, Rizo M, Huang H, Demeter S. Quantitative computed tomographic analysis in the diagnosis of dementia. Arch Neurol 